\title{
ISTVÁN BEJCZY, “TOLERANTIA: UN CONCEPTO MEDIEVAL"
}

\section{Título original: "Tolerantia: A Medieval Concept" Journal of the History of Idea: University of Pennsylvania Press, vol. 58, 1997, pp. 365-984}

\section{Traducción: Silvana Filippi}

La noción de tolerancia generalmente es considerada un producto de los tiempos modernos y en particular de la Edad de la Razón ${ }^{1}$. Los filósofos ilustrados, que sentaron las bases del liberalismo y de la democracia, a menudo son aclamados como los hombres que introdujeron la noción de tolerancia como un medio de garantizar el máximo de libertad a los miembros individuales de la sociedad. Escritos como la Epistola de tolerantia de John Locke y el Traité sur la tolérance de Voltaire prueban, en efecto, que la tolerancia era un tema importante en el pensamiento ilustrado. A veces se acepta que puede encontrarse una noción temprana de tolerancia, especialmente en los escritos de los humanistas cristianos como Erasmo. De hecho, "tolerancia erasmiana" es una frase habitual en los Países Bajos, donde a la gente le gusta vincular la única virtud de la que se precian abiertamente con el único autor holandés universalmente conocido.

Por el otro lado, la Edad Media no tiene reputación en favor de la tolerancia, cuya falta se atribuye generalmente a la influencia de una Iglesia poderosa que fue capaz, y estuvo dispuesta a ello, de suprimir todas las desviaciones importantes respecto de la verdad exclusiva que estaba convencida de poseer. Sólo la Reforma, se argumenta a menudo, forzó a la Iglesia a cambiar su actitud y a redefinir su relación con los disidentes. ${ }^{2}$ Como consecuen-

\footnotetext{
${ }^{1}$ Este artículo fue escrito en el Centro de Estudios sobre la Reforma y el Renacimiento y en el Pontifical Institute of Mediaeval Studies, Universidad de Toronto, subsidiado por la Netherlands Organization of Scientific Research (N.W.O.).

${ }^{2}$ Véase, por ejemplo, Joseph Lecler, Histoire de la tolérance au siècle de la Réforme (2 vols.; Aubier, 1955); Klaus Schreiner, Gerhard Besier, "Toleranz”, Geschichtliche Grundbegriffe, ed. Otto Brunner, Werner Conze, y Reinhart Koselleck (7 vols.; Stuttgart, 1972-92), VI, 445-605.
} 
cia, muchos estudios históricos sobre la idea de tolerancia comienzan recién en el siglo XVI. ${ }^{3}$

Esta representación de la historia de la tolerancia está, sin embargo, distorsionada. En la Edad Media la tolerantia era un concepto político altamente desarrollado y fue ampliamente aplicado tanto en la esfera eclesiástica como en la secular. Esta observación no es completamente nueva. En un número limitado de estudios, el concepto medieval de la tolerancia recibe la debida atención. Los más importantes de esos estudios son los de Joseph Lecler, Mario Condorelli y Klaus Schreiner, pero desafortunadamente ninguno de estos autores trata el tema de la tolerancia medieval de manera satisfactoria.

En su monumental Histoire de la tolérance au siècle de la Réforme (1955), Lecler no investiga sistemáticamente el término o el concepto de tolerancia medieval, sino que estudia brevemente la actitud adoptada por los autores escolásticos cristianos hacia los herejes y los paganos. De hecho, Lecler equipara tácitamente la noción de "tolerancia" con la de "libertad religiosa", un concepto que en verdad encontró poco apoyo entre los escolásticos medievales. ${ }^{4}$ El estudio de Condorelli (1960) es mucho más sistemático, pero tiene un alcance bastante limitado. Se concentra en el desarrollo de la tolerancia religiosa en el derecho canónico medieval entre los siglos XII y XIV. ${ }^{5}$ Los juristas canónicos de hecho acuñaron el concepto medieval de tolerantia con atención específica a la tolerancia religiosa, y por esta razón el trabajo de Condorelli sigue siendo importante y útil. Pero Condorelli no analiza la tolerantia medieval en todo su alcance, ni compara el concepto con posteriores usos del término.

El artículo de Schreiner sobre la tolerancia en Geschichtliche Grundbegriffe (1990) contiene una discusión detallada sobre el concepto de tolerancia y su desarrollo en la historia intelectual occidental. ${ }^{6}$ Schreiner ofrece una gran cantidad de material sobre los períodos patrístico y medieval, y sus representaciones de los hechos y desarrollos históricos son

\footnotetext{
${ }^{3}$ Véase, por ejemplo, Michel Peronnet (ed.), Naissance et affirmation de l'idée de la tolérance, XVIe et XVIIe siècle (Montpellier, 1988); Marijke Gijswijt-Hofstra (ed.), Een schijn van verdraagzaamheid. Afwijking en tolerantie in Nederland van de zestiende eeuw tot heden (Hilversum, 1989).

${ }^{4}$ Cf. la introducción de Lecler a la sección sobre la Edad Media (I, 93): "II semble donc, de prime abord, que le moyen âge n'apporte aucun témoignage en faveur de la liberté religieuse. En réalité la situation médiévale est moins simple qu'on ne l'imagine communément ..." (la cursiva es mía).

${ }^{5}$ Mario Condorelli, I fondamenti giuridici della tolleranza religiosa nell'elaborazione canonistica dei secoli XII-XIV (Milan, 1960).

${ }^{6}$ Schreiner escribió el artículo junto con Besier, pero las secciones sobre los desarrollos anteriores al 1600 son suyos. Este artículo se refiere sólo a esas secciones.
} 
generalmente correctos. Sus evaluaciones de los hechos, sin embargo, me dan la impresión de ser engañosas en lo que concierne a la Edad Media. Schreiner se reúsa a tomar en serio la tolerancia medieval. La pretensión de la religión cristiana de encarnar la verdad absoluta y su función como factor principal de integración de la sociedad habría impedido un desarrollo completo de la tolerancia; Schreiner incluso considera la cristiandad medieval como intolerante en su misma esencia. Tal como él sostiene:

Sólo cuando el temprano Estado moderno procedió a hacer de la religión natural el vinculum societatis que forma consensus en lugar de un sistema cerrado de creencia estableció espacios de acción libres en los cuales individuos y grupos podrían realizar sus derechos de libertad de creencia y conciencia. [...] Sólo la disolución de los vínculos históricamente desarrollados entre religión y justicia, que restituyó la libertad a la religión y la prudencia a la justicia, permitió la libre expresión de la religión en un espíritu de paciencia mutua. ${ }^{7}$

Podemos reprocharle a Schreiner varias imprecisiones. Primero, es discutible si la religión medieval representó un sistema cerrado que puede ser opuesto a los sistemas religiosos supuestamente más abiertos de la temprana historia moderna. La religión y el dogma medievales tenían, desde luego, una cierta elasticidad. Los ardientes debates religiosos en las universidades y la división de los teólogos en diferentes escuelas, especialmente en la tardía Edad Media, prueban que los teólogos podían ser muy críticos el uno del otro dentro de los límites de la ortodoxia. Es cierto que la herejía flagrante y obstinada fue castigada con la muerte, pero la cuestión de cuánto margen de maniobra tenían realmente los cristianos dentro de la Iglesia medieval en comparación con los creyentes postmedievales requiere un análisis cuidadoso en sí mismo -el hecho de que las transgresiones religiosas fueran suprimidas no dice nada acerca de cuán lejos debería llegar un cristiano para cometer una transgresión. Segundo, los lazos entre Iglesia y Estado estaban lejos de aflojarse después de la Edad Media, como sugiere Schreiner. El principio temprano moderno del cuius regio, eius religio indica más bien lo contrario, y teocracias posmedievales como la Ginebra de Calvino, la Inglaterra de Cromwell y la Massachusetts de Endicott no nos impactan como ejemplos de organizaciones particularmente abiertas y tolerantes. Pero las deficiencias más serias de Schreiner son sus ideas preconcebidas referidas a de qué se trata la tolerancia. También equipara la tolerancia con la libertad de religión. En su opinión, la tolerancia está

\footnotetext{
${ }^{7}$ Schreiner, 448, 524.
} 
intrínsecamente vinculada a la pluralidad o relatividad de la verdad (religiosa); ${ }^{8}$ dondequiera que tal pluralidad o relatividad no existe o no es reconocida, Schreiner niega la existencia de tolerancia "real".

En mi opinión, el concepto medieval de tolerancia contradice las afirmaciones de Schreiner. La tolerantia medieval es un ejemplo completamente acabado de lo que la tolerancia podría ser. Es un concepto aún más coherente y contundente que la noción bastante flexible de la tolerancia en el discurso político moderno, precisamente porque no tiene nada que ver con la libertad religiosa o la pluralidad de la verdad. De hecho, el esfuerzo de pluralizar la verdad (religiosa) en el temprano pensamiento moderno se relacionó con un serio retroceso de la tolerancia medieval.

En orden a fundamentar estas declaraciones, quiero elucidar el concepto medieval de tolerancia mediante la discusión de su uso en la literatura medieval erudita, especialmente en el derecho canónico y la escolástica, desde el siglo XII en adelante. A continuación, quiero señalar algunas diferencias importantes con las supuestas tendencias "tolerantes" en el temprano pensamiento moderno, tal como fueron ejemplificadas por Erasmo. Mis hallazgos, finalmente, me permitirán adelantar algunas observaciones críticas sobre la noción de "tolerancia" en su uso corriente.

Es posible distinguir tres significados diferentes de la tolerantia en las fuentes medievales y de la temprana modernidad, significados que se originaron en tres diferentes contextos culturales. En la Antigüedad, especialmente en los escritos estoicos, tolerantia significaba el soportar cualquier cosa que sea una carga para el cuerpo humano o, más a menudo, para la mente humana. La temprana Cristiandad desarrolló un segundo significado: tolerantia todavía indicaba la carga física o psicológica, pero con connotaciones religiosas. Se refería a la capacidad virtuosa de los individuos cristianos para soportar con calma cualquier sufrimiento de la existencia terrenal. En este sentido, como un sinónimo de patientia, el término aparece una vez en el Nuevo Testamento (2 Cor.1: 6) y con bastante frecuencia en los escritos de los Padres de la Iglesia. ${ }^{9}$ Tanto en su sentido clásico como en su sentido cristiano temprano, la tolerancia se refiere a la vida individual. Significa soportar las dificultades que afectan personalmente a los seres humanos. No obstante, como un concepto social

\footnotetext{
${ }^{8}$ Schreiner, 457: "Pluralität verlangt Toleranz".

${ }^{9}$ Ibid., 450-55; véase también Lecler, I, 65-92.
} 
y político, la tolerantia es una invención de la Edad Media. En la escritura erudita medieval tolerantia llegó a denotar -análogamente a algunos ejemplos incidentales en las obras de Agustín- la tolerancia de las personas malas (inmorales, heterodoxos, infieles) por parte de aquellos que tenían el poder de deshacerse de ellos. El objeto de la tolerancia en este tercer sentido eran personas y sus supuestos malos hábitos, personas que fueron vistas como una carga para la sociedad y no, al menos no principalmente, para los individuos. Por otra parte, el sujeto tolerante ya no era un individuo carente de poder, sino una poderosa colectividad que, si quisiera, podría destruir a las personas toleradas, pero no debería obrar así. Por lo tanto, la tolerancia implicaba la autocontención del poder político, la abstinencia de la fuerza correccional o destructiva por parte de las autoridades que gobiernan la sociedad. El terreno común entre los tres significados de tolerantia es la implicación de una actitud pasiva del bueno y del justo hacia las fuerzas del mal.

El desarrollo de la tolerantia como un concepto político fue especialmente promovido por el derecho canónico desde el siglo XII en adelante. Las dos principales colecciones del derecho canónico, el Decretum Gratiani de aproximadamente el 1140 (basado en gran medida en los Padres de la Iglesia, especialmente en Agustín) y las Decretales de Gregorio IX promulgadas en $1234,{ }^{10}$ contienen varias declaraciones sobre las circunstancias bajo las cuales las malas prácticas pueden quedar impunes. El verbo tolerare se usa con frecuencia en este contexto. El Decretum dedica una quaestio completa al asunto, en la que Graciano concluye -tal vez dándose cuenta de que ese tipo de hombre nunca puede ser purgado por completo de las malas intenciones ${ }^{11}$ - que el mal que no puede ser corregido sin perturbar la paz en la Iglesia debería más bien ser tolerado. ${ }^{12}$ En consecuencia, las Decretales establecen que muchas cosas que serían suprimidas si fuesen llevadas ante un tribunal, son toleradas con paciencia. ${ }^{13}$ Ambas colecciones de leyes señalan especialmente a los ritos judíos como prácticas con las cuales por derecho no se ha de interferir. ${ }^{14}$

\footnotetext{
${ }^{10}$ El Decretum es una compilación privada de textos de autoridades de la Biblia, de los Padres de la Iglesia y de autores medievales tempranos que funcionaron en la práctica como una fuente del derecho. Las Decretales de Gregorio IX (también llamadas Liber Extra y abreviado como X) son una colección oficial de decretos papales compilados por Raimundo de Peñafort (1175/80-1275). Las citas son del Corpus iuris canonici, ed. Aemilius Friedberg (2 vols.; Leipzig, 1879-81).

${ }^{11}$ C. 31 q. 1 c. 9 (Crisóstomo).

${ }^{12}$ C. 23 q. 4 c. 17 d.p.

${ }^{13}$ X 3.5.18 (Inocencio III).

${ }^{14}$ Véase, por ejemplo, D. 45 c. 3; X 5.6.3, 5.6.7, 5.6.9.
} 
Los canonistas medievales que comentaron estas declaraciones introdujeron y elaboraron el concepto de tolerantia como una noción judicial. Este desarrollo fue de la mano con la extensión de la jurisdicción eclesiástica sobre toda la humanidad. El Decretum se originó como una colección de reglas que definió la actitud de la Iglesia sólo hacia los cristianos. Con respecto a los no cristianos, Graciano había dejado a Dios el juicio sobre aquellos que están fuera de la fe (refiriéndose a 1Cor. 5:12-13). ${ }^{15}$ Posteriormente, los canonistas gradualmente abandonaron esta reticencia, afirmando finalmente que el Papa podría defender la ley natural contra cualquier persona en el mundo, independientemente de la fe de la persona en cuestión. ${ }^{16} \mathrm{Al}$ mismo tiempo, la noción de tolerancia se aplicó a todas las naciones y religiones por igual. El propio papa Inocencio IV reconoció, junto con su confirmación de la jurisdicción universal papal, que el Papa a veces se abstuvo de castigar infracciones a la ley natural no sólo por falta de poder real sino también porque el castigo parecía indeseable en ciertos casos. ${ }^{17}$ Comentaristas influyentes como Hostiensis (Enrique de Segusio, c. 1200-1270) y Johannes Andreae (c. 1270-1348), apoyando la opinión de Inocencio, declararon que tolerar a los incrédulos podría ser incluso un deber, siempre que no representaran una amenaza seria para el cristianismo. ${ }^{18}$

El concepto de tolerancia no se refería a un acto de no interferencia en absoluto por parte de la Iglesia. Raimundo de Peñafort dio la siguiente explicación en su Summa de iure canonico (c 1222/24):

La permisión se comprende de tres maneras diferentes. Primero, cuando es permitido algo que no está prohibido por ninguna ley [...] Segundo, cuando es consentido algo que va en contra de las reglas humanas [...] A esto se llama propiamente verdadera y absoluta permisión, y exime del pecado. El tercer tipo de permisión se produce cuando los males menores

\footnotetext{
${ }^{15}$ C. 23 q. 4 c. 16 d.p.

${ }^{16}$ Véase Walter J. Pakter, Medieval Canon Law and the Jews (Ebelsbach, 1988), 47-83.

${ }^{17}$ In V libros Decretalium commentaria (Venecia, 1570) X $3.34 .6 \S 6$.

${ }^{18}$ Hostiensis, In Decretalium libros commentaria (Venecia, 1581; facs. Turín, 1965) X 3.34.8, III f. 128v; Johannes Andreae, In Decretalium libros nouella commentaria (Venecia, 1581; facs. Turín, 1963) X 3.34.8, III f. 172v. Sus opiniones fueron frecuentemente repetidas en la tardía Edad Media; véase, por ejemplo, $P a$ normitanus (Nicolaus de Tudeschis, 1386-1445), Super Decretales (Perugia, 1509) X $3.34 .8 § 10$, V f. 168v (citando a Hostiensis). La pretensión eclesiástica de jurisdicción universal no fue, por lo tanto, un impedimento para la tolerancia religiosa, como sugiere Jeremy Cohen, The Friars and the Jews: The Evolution of Medieval Anti-Judaism (Ítaca, 1982), 262.
} 
están permitidos a fin de evitar otros mayores. Esto se llama permissio comparativa, y no exime del pecado. Sin embargo, debería llamarse tolerantia en lugar de permisión. ${ }^{19}$

La explicación de Raimundo trae a la luz dos características esenciales del concepto de tolerancia. En primer lugar, la tolerancia se aplica al mal. La tolerancia no implica que el carácter malvado del acto tolerado sea negado o atenuado; significa simplemente que ciertos actos malvados permanecen impunes. Ecclesia non approbat, sed permittit, explicaron varios comentaristas. ${ }^{20}$ La tolerancia no ofrecía licentia peccandi, sino sólo una liberatio a pena,${ }^{21}$ y fue concebida como no interferencia con prácticas que, sin embargo, eran inequívocamente consideradas repugnantes.

En segundo lugar, la tolerancia fue aplicada para evitar un mal mayor que el tolerado. Minus malum toleratur ut maius tollatur se decía a veces en la literatura jurídica. ${ }^{22}$ La tolerancia era el resultado de las oportunidades de ponderación. La no interferencia con ciertos actos malvados debería evitar la ocurrencia de peores males. Raimundo no fue el único canonista que entendió tolerantia como permissio comparativa. ${ }^{23}$ Algunos canonistas aspiraban a definir esta permissio de modo aún más preciso, como Johannes Andreae, que distinguió tres tipos de tolerancia: permissio simplex, la mera abstención de castigar actos malvados; permissio tollens impedimentum, que, además, obligó a la Iglesia a impedir que otras personas actuaran contra los actos malvados en cuestión; y permissio praestans iuva-

\footnotetext{
${ }^{19}$ Summa de iure canonico, ed. Xaverius Ochoa y Aloisius Diez, Universa bibliotheca iuris I.A (Roma, 1975), 1.5.4, 8-9.

${ }^{20}$ Johannes Teutonicus, Glossa D. 3 c. 4 ad v. permittit: "secundum hanc permissionem [tolerantia] dicit canon quod ea, quae permittimus, non approbamus". Las Glossa ordinaria (ca. 1216) son el comentario estándar sobre el Decretum; las citas son del Corpus iuris canonici in tres partes distinctum (Lyons, 1671). Véase también Geoffrey of Trani (†1245), Summa super titulis Decretalium (Lyons, 1519; facs. Aalen, 1968, 1992), f. 206; Hostiensis, Summa una cum summariis et adnotationibus Nicolai Superantii (= Summa aurea) (Lyons, 1537; facs. Aalen, 1962) V.11 § 4, f. 236. Cf. C. 31 q. 1 c. 9: "aliud est enim precipere, aliud permittere" (Crisóstomo); Antonius de Butrio (1338-1408), Commentarii in libros Decretalium (Venecia, 1578; facs. Turín, 1967), X 4.14.6 § 7, [VI] f. 37: “tolerantia haec generaliter non excusat a peccato". Véase también Condorelli, 134.

${ }^{21}$ Johannes Teutonicus, Glossa D. 45 c. 3 ad v. licentiam.

22 Rhetorica ecclesiastica (ca. 1160-80), ed. Ludwig Wahrmund, Quellen zur Geschichte des römischkanonischen Prozesses im Mittelalter I , 4 (Innsbruck, 1906), 20: "Tolerantia est de maiori duorum vel plurium malorum declinatio"; Summa "Elegantius in iure divino" seu Coloniensis (1169), ed. Gerardus Fransen y Stephanus Kuttner (New York-Ciudad del Vaticano, 1969-), I, 26: "tolerantia [est] de malis et mortalibus, cum minus toleratur ut maius tollatur"; Johannes Teutonicus, Glossa D. 3 c. 4 ad v. permittit: "illicitum permitti, ut magis illicitum vitetur ... appellatur tolerantia”. Véase también Condorelli, 23.

${ }^{23}$ Véase Johannes Teutonicus, Glossa D. 3 c. 4 ad v. permittit.
} 
men, el caso en el que se requirió que la Iglesia fomentara activamente la ocurrencia de algún acto malvado (por ejemplo, el castigo de clérigos criminales). ${ }^{24}$

Los principales grupos sociales que se beneficiaron de la tolerantia recomendada en el derecho canónico parecen haber sido los no cristianos, especialmente judíos y prostitutas. El concepto de tolerantia se desarrolló principalmente como una respuesta a la pregunta acerca de cómo las autoridades eclesiásticas deberían lidiar con las prácticas de la religión judía. ${ }^{25}$ Los ritos judíos fueron considerados un mal que debía ser tolerado; el mal mayor que así se impidió fue la conversión forzada de los judíos, pues la conversión al cristianismo tenía que ser una cuestión de libre albedrío. Además, los judíos estarían más dispuestos a abrazar la fe cristiana, argumentaron los canonistas, si fuesen tratados con benevolencia. ${ }^{26}$ En consecuencia, Johannes Andreae mencionó los ritos judíos como un ejemplo de actos que deberían cumplir con la permissio tollens impedimentum: la Iglesia no sólo debería dejar los ritos sin castigo, sino también impedir que otros interfirieran en ellos. ${ }^{27}$ Los mismos argumentos para la tolerancia fueron aplicados a otros no creyentes, especialmente a los musulmanes. El derecho canónico en general trató a judíos y musulmanes bajo los mismos rótulos, aunque los canonistas a menudo tomaron una postura más dura contra estos últimos porque, como resultado de las cruzadas, la cristiandad estaba en guerra con ellos. Los canonistas estuvieron de acuerdo, sin embargo, en que los musulmanes que vivían en paz con los cristianos no deberían ser atacados o expulsados. Otros infieles que vivían en las fronteras de la cristiandad (prusianos, lituanos) debían ser tratados de forma análoga. ${ }^{28}$ La tolerancia a la prostitución está expresada de modo menos marcado en el derecho canónico; con todo, la prostitución a menudo fue mencionada como un pecado que era legíti-

\footnotetext{
${ }^{24}$ In titulum de regulis iuris nouella commentaria (Venecia, 1581; facs. Turín, 1963), regula Peccatum $5.8 \S$ 4, f. 64.

${ }^{25}$ Para un estudio sobre la actitud de los canonistas véase Pakter, op. cit.

${ }^{26}$ Véase Goffredus de Trani, Summa f. 206; Hostiensis, In Decretal. X 5.6.7, V f. 31v; id., Summa aurea V.11, f. 235v-236v; Johannes Andreae, In Decretal. X 5.6.7, V f. 41v; también, por ejemplo, Antonius de Butrio, Commentarii X 5.6.7 § 3, [VII] f. 38A (citando a Hostiensis y Johannes Andreae); Panormitanus, Super Decretales X $3.34 .8 \S 15$, V f. 168v; Johannes de Anania (†1457), Super quinto Decretalium (Lyons, 1553) X 5.6.7 § 8, f. 73v-74 (citando a Johannes Andreae). Véase también Schreiner, 462-65.

27 Véase más arriba n. 24.

${ }^{28}$ Véase Peter Herde, "Christians and Saracens at the Time of the Crusades: Some Comments of Contemporary Canonists", Studia Gratiana, 12 (1967) = Collectanea Stephan Kuttner, II, 359-76; James Muldoon, Popes, Lawyers, and Infidels: The Church and the Non-Christian World 1250-1550 (Philadelphia, 1979); James M. Powell, “The Papacy and the Muslim Frontier", Muslims under Latin Rule, 1100-1300, ed. Powell (Princeton, 1990), 175-203.
} 
mamente permitido. ${ }^{29}$ Los mayores males que así se impedían, según las autoridades medievales, eran el adulterio (esto es, con mujeres honorables), la violación y la sodomía. ${ }^{30}$

En el siglo XIII, el concepto de tolerancia que se había elaborado en el derecho canónico se introdujo en la escolástica, donde se amplió su alcance apreciablemente. Los escolásticos consideraron la tolerancia como una actitud a adoptar no sólo por la Iglesia sino también por el Estado. Especialmente cuando estaban definiendo la relación del poder secular con los judíos, los escolásticos recurrieron con entusiasmo a la doctrina de la tolerantia del derecho canónico. La Summa theologica atribuida a Alejandro de Hales (hacia 11851245), por ejemplo, contiene una extensa defensa de la tolerancia hacia los ritos judíos, con un gran número de referencias a los escritos canónicos. ${ }^{31}$ La obra de Tomás de Aquino (1225-74) también ofrece buenos ejemplos. Particularmente iluminador es un pasaje de su Summa theologiae sobre los ritos de los infieles. Tomás respondió afirmativamente a la cuestión acerca de si los cultos no cristianos deberían ser tolerados por los gobernantes cristianos (con una referencia al Decretum Gratiani ${ }^{32}$ ). Los que están en el poder, explicó Tomás, con razón permiten ciertos males para que ningún bien sea destruido o males mayores los sustituyan. En consecuencia, la prostitución está permitida por el gobierno humano, porque, como dice Agustín, la sociedad sería devastada por la lujuria desenfrenada si la prostitución estuviera prohibida. Así, aunque los infieles pueden pecar por sus ritos, deben ser tolerados si se puede obtener algo bueno de ellos o si se evita algún mal. Por lo tanto, los ritos de los judíos deben ser tolerados, porque prefiguran la fe cristiana, que es un bien; pues de esta manera obtenemos testimonio de nuestra fe de parte de nuestros enemigos. Los ritos de los otros infieles, de los que ningún bien procede, pueden ser tolerados para evitar el escándalo o el odio hacia el cristianismo que podría ser el resultado de su supresión. ${ }^{33}$

La tolerancia por el bien que puede resultar del mal permitido parece haber sido la propia idea de Tomás. Esta idea no alteró el hecho de que el mal tolerado se mantuvo tan malo como siempre lo fue. Tomás alegó que los judíos pecan en sus ritos y los llamó “nues-

\footnotetext{
${ }^{29}$ Un estudio en James A. Brundage, "Prostitution in Medieval Canon Law", Sexual Practices and the Medieval Church, ed. Vern L. Bullough y Brundage (Buffalo, 1982), 149-60.

${ }^{30}$ Véase, por ejemplo, C. 32 q. 7 c. 11 (Agustín); Thomas de Chobham, Summa confessorum (c. 1220), citado en Schreiner, 471-72; Alexander de Nevo, Contra iudeos fenerantes (1441), ed. una cum Summa Pisanella (Venecia, 1482), f. A3v-4.

${ }^{31}$ Summa theologica, ed. PP Coll. S. Bonaventurae (5 vols.; Quaracchi, 1924-69), III, 728-31.

${ }^{32}$ D. 45 c. 3.

${ }_{33}$ Summa Theologiae, Opera omnia iussu Leonis XIII PM. edita (en lo sucesivo: ed. Leon.) IV-XII (Roma, 1888-1906), II.II.10.11; la cita de Agustín es de De ordine II, 4.
} 
tros enemigos". Su argumento muestra que uno no tenía por qué gustar de los judíos para ser tolerante; por el contrario, a uno tenían que disgustarle para ser tolerante, porque la tolerancia sólo se aplica al mal. La tolerancia no era un imperativo de amor, sino una restricción respecto de lo que uno odia. Es gracias a esta restricción, sin embargo, que a los judíos, en la concepción tomista, se les permitió vivir su propia vida dentro de los lazos de una sociedad cristiana.

Si pasamos al pequeño tratado sobre el gobierno de los judíos que Tomás escribió para la duquesa de Brabante, vemos la misma línea argumental. Tomás comenzó con la declaración de que los judíos, debido a su culpa por la crucifixión, están destinados a la esclavitud perpetua y por lo tanto podrían ser tratados como esclavos por los gobernantes cristianos. ${ }^{34}$ Sin embargo, argumentó Tomás, es nuestro deber conducirnos honestamente para con los que están fuera [del cristianismo], como dice el apóstol (1 Tes. 4:12). Los gobernantes cristianos deberían, por lo tanto, comportarse correctamente con sus súbditos judíos y no requerir nada más de ellos de lo permitido por la costumbre. ${ }^{35}$ Una vez más, Tomás no dijo que el gobernante debe aceptar a los judíos como si fueran buenos súbditos; en su visión, permanecen siendo pecaminosos que están por fuera [de la comunidad cristiana], pero precisamente porque están fuera los gobernantes cristianos tienen que comportarse con honestidad respecto de ellos. Tomás incluso concedió algo de espacio a la mala práctica de la usura con la que los judíos estaban conectados. Aunque los gobernantes harían mejor en obligar a los judíos a trabajar, en opinión de Tomás, tenían derecho a imponer impuestos sobre los ingresos que sus súbditos judíos extraían de la usura y gastarlos para el bien común. Tomás sabía muy bien que la usura estaba permitida por la ley humana como una herramienta necesaria para la prosperidad económica, aunque nunca recomendó la tolerancia de la usura de manera directa. ${ }^{36}$ En vista del hecho de que los gobernantes cristianos toleraban a los judíos y otros infieles principalmente debido a su utilitas, ${ }^{37}$ la limitada con-

\footnotetext{
${ }^{34}$ Sobre la teoría del servitus iudaeorum véase Salo W. Baron, A Social and Religious History of the Jews (18 vols.; New York-Philadelphia1, 952-83 [2]), IX, 135ff.; XI, 3ff. Para su inserción en el derecho canónico véase X 5.6.13 (Inocencio III).

${ }^{35}$ Epistola ad ducissam Brabantiae, ed. Leon. XLII (Roma, 1979), 375-76, que recuerda a X 5.6.9 (Clemente III).

${ }^{36}$ Ibid.; cf. Summa theologiae II.II.78.1 ad 3, citado a continuación en n. 44.

37 Véase Powell, op. cit., 203.
} 
cesión de Tomás para con los prestamistas judíos debió haber funcionado como un fuerte estímulo para la tolerancia de los judíos. ${ }^{38}$

Argumentos comparables a los de Tomás de Aquino se pueden encontrar con bastante frecuencia en la literatura política moralizante de la Baja Edad Media. Muchos autores recurrieron a la idea de tolerantia con el fin de demostrar cómo controlar factores malvados en una sociedad cristiana. Se refieren especialmente al principio de oportunidad, como en el caso de Ptolomeo de Lucca (c. 1236-c. 1327), quien escribió una continuación del speculum principis que su maestro Tomás de Aquino había compuesto para el rey de Chipre. Según Ptolomeo, el mal de la prostitución tuvo que ser tolerado porque previno el mal mayor de la sodomía. Él atribuye falsamente a Agustín la comparación entre la prostitución y el alcantarillado de un palacio: "Elimina la cloaca, y llenarás el palacio de hedor; elimina a las prostitutas y llenarás el mundo de sodomía". ${ }^{39}$ En parte porque se creía que Agustín realmente había dicho estas palabras y en parte porque se creía que el propio Tomás de Aquino había citado a Agustín en su speculum principis, este pasaje se convirtió en un argumento de autoridad en favor de la tolerancia de las prostitutas en la Baja Edad Media. No sólo otros escritores se refieren a esto para reforzar sus propios argumentos, sino que también lo hicieron los gobernantes de las comunidades urbanas que tuvieron que defender la existencia de maisons de tolérance dentro de los límites de sus ciudades. ${ }^{40}$ Nuevamente, la tolerancia no tiene nada que ver con la aprobación. La prostitución no estaba permitida porque fuera considerada un bien, sino porque su supresión resultaría en males aún mayores. ${ }^{41}$

\footnotetext{
${ }^{38}$ Por lo tanto, no se justifica, como lo hace Cohen, incluir a Tomás sin más entre los teólogos mendicantes que contribuyeron a la desaparición gradual de la población judía de Europa. Cohen no tiene en cuenta los pasajes de la Summa theologiae y la Epistola ad ducissam discutidos aquí, aunque estos textos fueron extensamente utilizados por los autores de finales de la Edad Media que debatieron sobre la tolerancia hacia los judíos. Por otra parte, la influencia del derecho canónico sobre la escolástica en materia de tolerancia invalida la distinción de Cohen entre papas y canonistas tolerantes, por un lado, y mendicantes intolerantes por otro una distinción que de todos modos es poco convincente, ya que el canonista Raimundo de Peñafort (que dio una definición autorizada de tolerancia, como hemos visto anteriormente) es representado por Cohen como el genio malvado detrás de la intolerancia mendicante.

${ }_{39}$ De regimine principum, ed. Raymundus M. Spiazzi, Divi Thomae Aquinatis ... Opuscula philosophica (Roma, 1954), IV, 14 (1073).

${ }^{40}$ Véase Jacques Rossiaud, Medieval Prostitution, tr. Lydia G. Cochrane (Oxford, 1988), 81 n. 17; Schreiner, 471-72. La expresión "maison de tolérance" fue usada en la Francia tardomedieval; véase Schreiner, 458.

${ }^{41}$ Véase Peter Schuster, Das Frauenhaus. Städtische Bordelle in Deutschland, 1350 bis 1600 (Paderbom, 1992), 212. Judíos y prostitutas parecen haber sido tratados casi de la misma manera en las ciudades tardomedievales; véase ibid. 212-13; Leah L. Otis, Prostitution in Medieval Society: The History of an Urban Institution in the Languedoc (Chicago, 1985), 69-70; Diane Owen Hughes, "Distinguishing Signs: Ear-Rings, Jews, and Franciscan Rhetoric in the Italian Renaissance City", Past and Present, no. 112 (1986), 3-59.
} 
Además de judíos y prostitutas, grupos marginados como los leprosos, los locos y los mendigos también parecen haberse beneficiado de la idea de tolerancia. En la Edad Media tardía la tolerantia se había convertido en un argumento para justificar la existencia de toda desviación social, especialmente en la comunidad urbana. ${ }^{42}$ Esto no permite afirmar que la sociedad medieval en la realidad fue siempre tolerante. Pogromos contra los judíos y expulsiones de personas marginales tanto como no cristianas ocurrieron efectivamente. Pero la teoría de la tolerantia fue defendida por los papas, los canonistas y muchos autores influenciados por ellos, ${ }^{43}$ que sirvieron al menos en un nivel moral como un impedimento para la destrucción ciega de lo que hoy llamaríamos "alteridad". Sin duda, esta teoría no implicaba que los gobernantes mundanos y eclesiásticos dieran por sentado todo mal. La tolerancia, debería repetirse, se extendió a males menores que se consideraron útilmente dejados sin interferencia. Como argumentó Tomás de Aquino, el gobierno humano debería proceder contra los vitia graviora, como el robo y el asesinato, pero debería dejar impunes los pecados menores sin aprobarlos, ya que no se puede esperar que todos los ciudadanos sean perfectos. Los males menores podrían incluso ser rentables para el Estado, y dejar margen para ellos podría consecuentemente ser un acto de buen gobierno. ${ }^{44}$

Si ciertos fenómenos deben ser considerados vitia graviora intolerables o no está, por supuesto, abierto a debate. Ni Tomás ni la mayoría de sus contemporáneos aceptaron la herejía. En el mismo período que dio a luz la idea de tolerancia, el cristianismo se hizo cada vez más intolerante con la disidencia religiosa tanto en la práctica como en la teoría. Incluso los estudiosos que, con Richard Kieckhefer, combaten la consideración de la Inquisición como una agencia represiva monolítica dirigida por Roma, no cuestionan el hecho de que "los clérigos medievales a partir del siglo XII en adelante claramente desean ejercer un con-

\footnotetext{
42 Véase Frantisek Graus, "Randgruppen der städtischen Gesellschaft im Spätmittelalter”, Zeitschrift fur historische Forschung, 4 (1981), 385-437. Gente de mala fama como los músicos callejeros pagaban "dinero de tolerancia" para quedarse en la ciudad. Véase Schreiner, 450, 472.

43 Powell, "Introduction", Muslims under Latin Rule, 5-7 (en cuanto a la tolerancia religiosa); Pakter, 27: "Ningún canonista ha abogado nunca por el exilio de los judíos interna o externamente".

${ }^{44}$ Summa theologiae I.II.93.3 ad 3; I.II.96.2; I.II.101.3 ad 2: "sapientis legislatoris est minores transgressiones permittere, ut maiores caveantur"; II.1.78.1 ad 3: "leges humanae dimittunt aliqua peccata impunita propter conditiones hominum imperfectorum, in quibus multae utilitates impedirentur si omnia peccata districte prohiberentur poenis adhibitis. Et ideo usuras lex humana concessit, non quasi existimans eas esse secundum iustitiam, sed ne impedirentur utilitates multorum".
} 
trol más estricto sobre los miembros de la Iglesia y definir más estrecha y precisamente los límites de la creencia y la conducta permitidas". ${ }^{45}$

Otro fenómeno que fue generalmente considerado intolerable fue la homosexualidad. ${ }^{46}$ A los herejes y homosexuales ni siquiera en teoría se les permitió morar en los márgenes de la sociedad, como a los judíos y a las prostitutas. Herejía y homosexualidad no fueron vistos como males menores que la sociedad podía permitirse. La herejía ponía en peligro el núcleo mismo de la civilización cristiana, mientras que a la homosexualidad se la percibía como amenaza a la distinción entre los sexos, la principal distinción que la civilización cristiana mantuvo dentro de sus propios rangos. La tolerantia era una forma de comportarse honestamente hacia los que están por fuera [de la comunidad cristiana]; hacia los que están dentro, prevaleció el rigor.

Desafortunadamente, la diferencia última es frecuentemente desatendida en la erudición moderna, que tiende a tomar la marginación y el exterminio de grupos sociales desviados como dos facetas de uno y el mismo proceso de "exclusión". ${ }^{47}$ En su contexto medieval, sin embargo, la marginación es, paradójicamente, una forma de incorporar grupos desviados a la sociedad, aunque en sus esferas externas. ${ }^{48}$ Sólo el exterminio de los grupos desviados en el patíbulo o la estaca puede ser considerado exclusión real, como una forma de deshacerse del mal cuando se sentía que la tolerancia estaba fuera de lugar, como fue el caso con herejes, homosexuales y delincuentes comunes. Para la exclusión total y final del mal, sin embargo, los cristianos medievales tenían que esperar el Juicio Final. Durante el

\footnotetext{
45 Richard Kieckhefer, "The Office of Inquisition and Medieval Heresy: The Transition from Personal to Institutional Jurisdiction”, Journal of Ecclesiastical History, 46 (1995), 36-61:40. El artículo de Kieckhefer resume la discusión sobre la naturaleza de la Inquisición provocada por su Repression of Heresy in Medieval Germany (Philadelphia, 1979).

${ }^{46}$ Véase John E. Boswell, Christianity, Social Tolerance and Homosexuality: Gay People in Western Europe from the Beginning of the Christian Era to the Fourteenth Century (Chicago, 1980); para Tomás de Aquino, véase Summa theologiae II.1.154.12. Graus, 399, señala el hecho de que los herejes y los homosexuales eran los dos principales grupos "marginales" que no eran tolerados en la sociedad medieval tardía.

47 Véase Robert I. Moore, The Formation of a Persecuting Society: Power and Deviance in Western Europe, 950-1250 (Oxford, 1987); véase también Graus, 433: “ihr gemeinsames Kennzeichen [de grupos marginales] war nur, dass sie von der Gesellschaft nicht integriert wurden”. Schuster, 212, argumenta con razón que la tolerancia de las prostitutas era un medio de integrarlas en la sociedad, a pesar del hecho de que eran universalmente despreciadas.

${ }^{48}$ Michel Foucault, Histoire de la folie à l'âge classique (París, 1961), 14: "la situation liminaire du fou à l'horizon du souci de l'homme médiéval" es expresada "par le privilège qui est donné au fou d'être enfermé aux portes de la ville; son exclusion doit l'inclore; s'il ne peut et ne doit avoir d'autre prison que le seuil luimême, on le retient sur le lieu du passage. Il est mis à l'intérieur de l'extérieur, et inversement'.
} 
saeculum, los males menores tenían que ser soportados e incluso podrían ser usados en aras del bien común.

La temprana historia moderna ofrece una imagen diferente a este respecto. El proceso de pluralización de la verdad religiosa parece haberse iniciado en el siglo XVI. Especialmente antes del comienzo de la Reforma, los humanistas, ante todo aquellos que estaban activos al norte de los Alpes, abogaban por una moderada diversidad en el ámbito de la doctrina y la práctica cristianas, introduciendo una libertad que sus predecesores medievales no habían estado dispuestos a conceder. Autores como Erasmo aborrecieron las disputas doctrinales y estuvieron mucho más interesados en restaurar una verdadera piedad cristiana, que podría hacerse sentir de diferentes maneras. No hay certeza respecto de si la relativa libertad de pensamiento y acción religiosos prevista en el humanismo cristiano realmente dejó más espacio para los fieles en comparación con la práctica medieval, en la que coexistían opiniones divergentes (después de todo, uno de los reproches humanistas más frecuentes a los teólogos escolásticos fue precisamente que nunca estuvieron de acuerdo el uno con el otro). Sin embargo, Erasmo y sus colegas humanistas defendieron al menos la idea de la flexibilidad de la verdad cristiana como una cuestión de principios.

Es la actitud apaciguadora de Erasmo en una era de creciente polarización religiosa lo que ha inspirado la noción de "tolerancia erasmiana". ${ }^{49}$ Esta noción, sin embargo, es bastante inadecuada. Erasmo nunca recomendó sus ideas sobre el asunto en nombre de la tolerancia, como ha argumentado Mario Turchetti. ${ }^{50}$ Para Erasmo la tolerantia era una elección por el menor de dos males. Sin embargo, no consideró la relativa libertad de creencia que defendió como un mal menor que sería mejor dejar sin interferencia para evitar cosas peores, sino más bien como algo normal y aceptable, de modo que la cuestión de la tolerancia era irrelevante. Cualesquiera puedan haber sido los méritos de sus puntos de vista, el término "tolerancia" no es correcto. La renuencia a rechazar las opiniones de los demás no es lo mismo que tolerar opiniones que uno realmente rechaza. De hecho, Erasmo reconoció

\footnotetext{
${ }^{49}$ Véase, por ejemplo, Wallace K. Ferguson, "The Attitude of Erasmus towards Toleration", Persecution and Liberty: Essays in Honor of George Lincoln Burr (New York, 1931), 171-81; Lecler, I, 133-49; Myron P. Gilmore, "Les limites de la tolerance dans l'oeuvre politique d'Erasme", Colloquia Erasmiana Turonensia (2 vols.; París-Toronto 1972), 713-36; Karl Heinz Oelrich, "Zum Toleranzbegriff des spaten Erasmus von Rotterdam", Festgabe für Ernst Walter Zeeden (Münster, 1976), 248-59; Manfred Hoffmann, "Erasmus and Religious Toleration", Erasmus of Rotterdam Society Yearbook, 2 (1982), 80-106.

50 "Une question mal posee: Erasme et la tolerance. L'idee de sygkatabasis", Bibliothèque d'Humanisme et Renaissance, 53 (1991), 379-95. Véase también la próxima nota.
} 
varias formas de ortodoxia, que es bastante diferente de permitir formas de heterodoxia. Es en nombre de la unidad y la concordia entre los cristianos que desarrolló la idea de una diversidad religiosa inocua. 51

Hacia la heterodoxia real, Erasmo no solía ser indulgente. Desde su punto de vista, las opiniones que no se podían conciliar con la fe cristiana tal como él la concibió (más condescendiente aun en comparación con algunos contemporáneos) tenían que ser reprimidas si fuese necesario incluso con la pena de muerte. Por supuesto se tenía que tratar de curar a los herejes antes de infligirles la pena capital, pero si ningún otro remedio fuese efectivo, había que amputar los miembros heréticos del cuerpo social para prevenir la contaminación de toda la comunidad. ${ }^{52}$ Cuando la herejía estuviese acompañada de insurrecciones, los malhechores debían incluso ser ejecutados sin vacilación, ${ }^{53}$ si no una parte importante de la sociedad sería afectada; porque una guerra religiosa sería un mal mayor que la existencia de los herejes. Esta última línea de pensamiento recuerda a la tolerancia medieval, aunque Erasmo agregó que la permisión de la herejía sólo debería ser una solución provisional: con el paso del tiempo, la sociedad tenía que ser purgada del monstruo de la herejía tan pronto como se presentase la oportunidad. ${ }^{54}$ Respecto de los herejes, entonces, Erasmo fue, por lo general, no menos intransigente que los teólogos medievales. ${ }^{55}$ Sólo después de su muerte una generación de teólogos tanto católicos como protestantes elaboran la idea de que el mal de la herejía debería en principio ser tolerado en caso de necesidad política, sobre todo cuando la tolerancia podría prevenir el maius malum de una masacre entre los ciudadanos. ${ }^{56}$

\footnotetext{
${ }^{51}$ Schreiner, 473, observa con razón que Erasmo no usa el término "tolerantia" para denotar sus ideas sobre la paz y la libertad religiosas, sino "pax" y "concordia”. Véase también Lecler, I, 125: “Aussi bien leur ideal [el de los humanistas cristianos] n'est pas tant la tolerance que la reduction des divergences religieuses par un loyal effort de conciliation". En consecuencia, el término "tolerantia" está ausente de los tratados del siglo XVI sobre la pacificación religiosa, como la Paz de Augsburg (1555), que emplea el término "concordantia" (Schreiner, 447).

52 Véase Adversus monachos quosdam hispanos, Opera omnia, ed. Joannes Clericus (10 vols.; Leiden 1703-6; de aqui en más LB), IX 1054B, 1056B, 1059E.

${ }^{53}$ Véase, e.g., Opus epistolarium Des. Erasmi Roterodami, ed. Percy S. Allen et al. (12 vols.; Oxford, 190658; en adelante: Allen), Epp. 1526: 155-59, 1690: 104-5; Supputatio errorum Beddae LB IX 581B; Adversus monachos LB IX 1056B; Epistola contra pseudevangelicos, Opera omnia (Amsterdam, 1969- ; en lo sucesivo: ASD), IX-1 288/137-41.

54 Véase Allen, Epp. 1924: 32-35, 2366: 51-55. Lecler, I, 138, piensa que en Ep. 2366 Erasmo aplica la tolerancia tomista hacia los infieles de la Summa theologiae II.II.10.11 a los herejes cristianos.

55 Vita Hieronymi: "en materia de herejía la tolerancia es un error, no una virtud", The Collected Works of Erasmus (Toronto, 1974-; en adelante: CWE), 61 44; Erasmi Opuscula. A Supplement to the Opera omnia, ed. W. K. Ferguson (The Hague, 1933), 165: 868-70.

56 Véase Lecler, I, 289-95; II, 197-203. Joannes Lensaeus (1541-93) aplica explícitamente a los herejes el argumento de Tomás de Aquino a favor de la tolerancia a los infieles.
} 
Sin embargo, hay algunas excepciones importantes a la falta de indulgencia de Erasmo hacia la herejía. Al exponer la parábola del trigo y la cizaña del Evangelio de Mateo (13: 24-30), Erasmo declaró explícitamente que, según Cristo, la mezcla del trigo (buenos cristianos) y la cizaña (malos cristianos, en particular los herejes) tenía que ser tolerada hasta la conclusión de la historia, cuando Dios separaría a los dos en el Juicio Final. ${ }^{57}$ La perspectiva puede ser calificada como genuinamente tolerante, y de hecho como un apartamiento respecto de la rigidez medieval. Sin embargo, cuando el autor luterano Gerard Geldenhouwer publicó en 1529 una selección de las declaraciones de Erasmo en favor de la tolerancia de los herejes, Erasmo se molestó. En su respuesta a Geldenhouwer, Erasmo afirmó nunca haber dicho que los herejes no debían ser ejecutados, sino sólo que uno no debería desenvainar inmediatamente la espada después de cualquier acusación de herejía de cualquier monje o teólogo, porque la caridad exigía que primero se intentara ayudar al caído. En cuanto a la parábola del trigo y la cizaña, Erasmo argumentó que no sacar la cizaña sólo se aplica a la Iglesia primitiva y a los apóstoles que no tenían otra espada que la palabra de Dios, ${ }^{58}$ pero que eso no implicaba ninguna restricción del poder de los gobernantes mundanos que usaron espadas reales contra los herejes. ${ }^{59}$

La posición general de Erasmo con respecto a la herejía, fue, entonces, bastante tradicional. Pero si no abogó sistemáticamente por la extensión de la tolerancia al campo de la herejía, ¿qué actitud adoptó hacia las visiones medievales de la tolerancia?

Aunque el término tolerantia en la obra de Erasmo se encuentra sobre todo en su sentido clásico y bíblico, ${ }^{60}$ algunos ecos de la tolerantia medieval se pueden encontrar tam-

\footnotetext{
57 Paraphrasis in Matthaeum LB VII 80E-F. Cf. Supputatio LB IX 580Cff.; Adversus monachos LB IX 1054Bff.; Ad censuras facultatis theologiae Parisiensis LB IX 904Fff.; Apologia ad blasphemias Stunicae LB IX 373C; Commentarius in Psalmum II ASD V-2 145/539-40; Allen Epp. 916: 244, 1202: 10ss., pero por otra parte 2583: 18-20.

${ }^{58}$ En el mismo sentido: Divinationes ad notate per Beddam LB IX 464A-C; Supputatio LB IX 582A; Adversus monachos LB IX 1056D.

${ }^{59}$ Contra pseudevangelicos ASD IX-1 287/107-15, 288/126-31. En su discusión sobre el uso que hace Erasmo de la parábola, Corelis Augustijn, Erasmus: His Life, Works, and Influence, tr. J. C. Grayson (Toronto, 1991), 177-78, ignora la retractación de Erasmo (¡aun cuando Contra pseudevangelicos fue editado por Augustijn mismo!) y elogia la "súplica de tolerancia" de Erasmo. Para similares tergiversaciones véase Oelrich y especialmente Hoffmann, 106.

${ }^{60}$ Erasmo a menudo mencionaba a Sócrates como un ejemplo de "tolerantia": De conscribendis epistolis ASD I-2 413/13-414/1, Colloquia ASD I-3 644/50-51, Encomium matrimonii ASD I- 5 398/178-80, Christiani matrimonii institutio LB V 660A. Para la "tolerantia" como una virtud cristiana (Erasmo conservó el término en 2 Cor. 1: 6 en su traducción del Nuevo Testamento y lo agregó en 2 Te. 1: 4 y Sant. 5:11) véase por ejemplo Epistola de philosophia evangelica LB VI *5; Allen Epp. 710: 85, 1177: 44. Con Erasmo el verbo "tolera-
} 
bién, especialmente con respecto a los judíos, ${ }^{61}$ para quienes Erasmo parece haber dado por sentada la tolerancia. A diferencia de algunos de sus contemporáneos, Erasmo nunca pidió la expulsión de los judíos o el uso de la violencia contra ellos. Tampoco tomó una posición firme contra los actos de violencia de los que los judíos fueron víctimas en su época. Aparentemente, la tolerancia de los judíos no le interesaba mucho a Erasmo; todo lo que podemos decir es que al menos no se opuso a ello. No obstante, está claro a partir de sus escritos que no le gustaban los judíos. Ni siquiera sería imposible acusar a Erasmo de antisemitismo. Pero en contra de lo que algunos académicos piensan, ${ }^{62}$ éste no es un argumento en contra de la tolerancia erasmiana. La tolerancia se aplica sólo al mal; por lo tanto, si Erasmo no hubiera considerado a los judíos malvados en algún sentido, para él allí no habría habido nada que tolerar. A Erasmo no le gustaban los judíos, pero él tampoco cuestionó su derecho de existencia en la sociedad cristiana, y esto es exactamente lo que lo hace tolerante (aunque sus declaraciones sobre el tema son bastante débiles en comparación con la tradición medieval). La aversión de Erasmo hacia los judíos es un requisito previo de su tolerancia, no un impedimento para ello.

Hacia las personas marginales distintas de los judíos que en la tradición medieval se encontraron con la tolerancia en la teoría y, a menudo también en la práctica, Erasmo parece haber sentido la necesidad de tolerar aún menos, y algunas veces se declaró explícitamente en contra de ello. No parece haber favorecido la tolerancia de las prostitutas ${ }^{63}$ (en realidad la prostitución se prohibió en toda Europa durante el curso del siglo XVI), y se expresó repetidamente en contra de la tolerancia de los mendigos ${ }^{64}$ y de otras personas que, en su opinión, eran inútiles y dañinas para la sociedad. Como lo expresó en su Institutio principis christiani:

... Es mucho mejor garantizar que no se cometan delitos en absoluto que castigarlos una vez que han sido perpetrados. Esto se logrará si el príncipe puede destruir, si es posible, o al

re" parece, en todos sus significados, ser sinónimo de "ferre", cf. Apophthegmata LB IV 314A: "Fert autem qui tolerat".

${ }^{61}$ Cf. e.g., Declarationes ad censuras Lutetiae vulgatas LB IX 909B, Ecclesiastes ASD V-5 254/232-34, Interpretatio in Psalmum LXXXVASDV-34 06: 90ss., Paraphrasis in Epistolam Pauli ad Romanos LB VII 808F, Allen, Ep. 2443: 314-16; véase Shimon Markish, Erasmus and the Jews, tr. Anthony Olcott (Chicago, 1986), 66-111.

${ }^{62}$ Véase, por ejemplo, Heiko A. Oberman, The Roots of Anti-Semitism in the Age of Renaissance and Reformation, tr. James I. Porter (Philadelphia, 1984), 38-40.

${ }^{63} \mathrm{Cf}$. por ejemplo Institutio matrimonii LB V 719F-720A.

${ }^{64}$ Cf. Colloquia ASD I-3 258/823-26, 437/143-45; Allen, Epp. 964: 50-54, 967: 20-22; y cf. Juan Luis Vives, De subventione pauperum (1526). 
menos controlar y reducir cualquier cosa que ha notado como una posible fuente de comportamiento criminal ... El príncipe vigilante, por lo tanto, se asegurará de que tenga la menor cantidad posible de ociosos entre sus súbditos, ya sea haciéndolos trabajar o desterrándolos del Estado. ${ }^{65}$

Aquí Erasmo defiende la idea humanista típica de que el príncipe, como educador de su pueblo, debería enseñar a sus súbditos cómo comportarse como buenos ciudadanos y abstenerse del mal. La afirmación de que el príncipe debe cortar todo el mal social de raíz, en lugar de dejarlo crecer para castigarlo, era un lugar común en los escritos políticos renacentistas. Al contrario de la opinión medieval, el mal no debía ser tolerado, ni en el centro ni en los márgenes de la sociedad cristiana. Ilustrando su punto de vista con la misma metáfora médica que utilizó con respecto a la herejía, Erasmo afirmó que las partes dañadas del cuerpo social tenían que ser eliminadas antes de que contaminaran el conjunto, ya sea devolviéndoles la salud o amputándolos. ${ }^{66}$ De ninguna manera podría tolerarse el mal social en su estado de depravación. No sólo se contemplaron aquí los vitia graviora tradicionales, sino que también lo fueron todos los tipos de degradación moral, cuyo efecto era mucho más duro, en opinión de Erasmo, que el control estatal de la conducta de los ciudadanos. ${ }^{67}$ Aunque sería injusto describir a Erasmo, o a los humanistas cristianos en general, como puramente intolerantes - podríamos señalar varios pasajes de la obra de Erasmo que abordan menos inflexiblemente el mal social ${ }^{68}$ - uno no puede pasar por alto las tendencias en el pensamiento político renacentista a luchar contra todos los elementos malvados en la socie-

\footnotetext{
${ }^{65}$ Institutio CWE 27 266-67, ASD IV-1 196/916-198/954. El pasaje es seguido por una enumeración de holgazanes, entre los que Erasmo cuenta a mendigos, granjeros, vendedores ambulantes, usureros, comerciantes, proxenetas, administradores de propiedades, guardabosques, cortesanos, soldados, nobles decadentes y muchos monjes y profesores universitarios. "Si el príncipe destierra de su reino a todos esos semilleros del crimen", concluye Erasmo, "habrá mucho menos para que castiguen sus leyes" (CWE 27 268, ASD IV-1 198/971-72).

${ }^{66}$ Ibid., ASD IV-1 196/928-197/933.

${ }^{67}$ Ibid., ASD IV-1 198/990-93. Una excepción es la defensa calificada de Erasmo del matrimonio de los clérigos como un "minus malum" (Appendix de scriptis Clichtovei LB IX 81 IF) para prevenir el libertinaje.

${ }^{68}$ En la Institutio Erasmo señala dos veces la posibilidad de la tolerancia del mal (ASD IV-1 173/213-16, 187/675-78) y afirma que difícilmente se puede esperar que todos los hombres sean buenos (140/116). Cf. también Allen, Ep. 858: 281-83. Para un eco literal de la idea medieval de tolerancia véase Erasmus' Annotations to the New Testament, ed. Anne Reeve y M. A. Screech (3 vols.; London, 1986-93), I, 213 (sobre Lucas 22:36): "Postremo sunt in rebus humanis multa necessaria mala, quae tolerantur eo quod excludant maiora mala, non probantur, ut Evangeliae doctrinae".
} 
dad y excluirlos en lugar de incorporarlos si esto parecía ser oportuno, como lo habían recomendado los autores medievales. ${ }^{69}$

La razón principal de la actitud intransigente de Erasmo ante el mal social parece ser su idea de que sólo cuando uno hace esfuerzos para hacer realidad la situación ideal se puede esperar producir un estado de cosas incluso modestamente mejor. En su comentario al adagio "Perciba la cima y a medio camino será suya", Erasmo atacó a los escolásticos que debatieron la medida en que era permisible ceder al mal, ya que era mejor combatir el mal en todas sus formas: sólo esto conduciría eventualmente a mejoras de algún tipo. ${ }^{70}$ En su prefacio a la edición de 1518 del Enchiridion militis christiani encontramos el mismo argumento. Después de haber criticado a los escolásticos por no dar nunca instrucciones claras para la conducta humana sino indicar en cambio lo que era tolerabilis, Erasmo explicó que el objetivo más alto -Cristo y su enseñanza en toda su pureza- "debe ser fijado antes que todos los demás, para que al menos podamos lograr algo a mitad de camino". ${ }^{71}$ Así Erasmo criticó la tradición medieval no por mostrar una falta de tolerancia sino por tenerla en demasía. Contentarse con el menor de dos males no era una opción seria para él. Como lo expresó en Antibarbari: "Algo que se tolera incluso puede ser agradable cuando se compara con algo peor; pero agradará mucho más si se transforma en algo mejor". ${ }^{72}$

La disposición de Erasmo a continuar la tradición medieval de la tolerancia es, entonces, notablemente baja. Sin embargo, hizo un uso extensivo del concepto de tolerantia en un campo que comúnmente se ha pasado por alto: sus polémicas contra los protestantes. Oponiéndose él mismo a la ruptura radical del luteranismo respecto de la Iglesia medieval una ruptura que, según Erasmo, se basó en la idea de que una vez que se fundara una nueva Iglesia, la religión y la moralidad estarían seguras- frecuentemente recurrió a la idea de la tolerancia. Insistió en que era una tontería pensar que la nueva Iglesia sería una comunidad santa protegida contra la descomposición. El mal, sostenía Erasmo, era intrínseco a la existencia terrenal y, por lo tanto, debía ser tolerado en cualquier institución humana. En su invectiva contra el luterano Geldenhouwer afirmó:

\footnotetext{
${ }^{69}$ Para una discusión más dellallada véase mi Pape Jansland en Utopia. De verbeelding van de beschaving van middeleeuwen en renaissance (Nimega, 1994).

${ }^{70}$ Adagia II iii 25, CWE 33 142-43, LB II 492A.

${ }^{71}$ CWE, Ep. 858:346-51 (Allen, 324-29).

${ }^{72}$ CWE 23 79, ASD I-1 101/6-8.
} 
Mientras la red de la Iglesia sea rastreada a través del curso de la historia terrenal y aún no haya llegado a la orilla, se debe tolerar la mezcla del bien y del mal; siempre ha sido el caso y siempre será el caso de la condición humana que produce más amargura que miel. ${ }^{73}$

Si las faltas humanas fuesen corregibles, continuó Erasmo, se debería ser cuidadoso sólo para eliminar los errores de la institución en juego, no la institución misma. Pero los protestantes fueron cualquier cosa menos cuidadosos y destruyeron todo. Invirtiendo la parábola de Mateo contra Geldenhouwer, Erasmo escribió: “Ustedes sacan el trigo junto con la cizaña o, más bien diría, sacan el trigo en lugar de la cizaña". ${ }^{74}$ Tolerar la cizaña, entonces, era una solución mejor. Erasmus declaró en Hyperaspistes I, en el que atacó a Lutero directamente:

Sé que en esta iglesia, a la que llamas papista, hay muchas personas que me desagradan: pero también veo tales hombres en tu iglesia. Sin embargo, el mal con el que estamos familiarizados es tolerado más fácilmente. Por lo tanto, voy a tolerar a esta iglesia hasta que vea una mejor... El que mantiene el curso medio entre dos males diferentes no es un navegante infeliz. $^{75}$

Aquí Erasmo adopta una actitud tolerante en el sentido medieval del término, permitiendo el mal menor del catolicismo deteriorado para prevenir el mal mayor de la anarquía protestante. Incluso una tiranía moderada de la superstición parecía más tolerable para él que una revolución total. ${ }^{76}$ Supersticiones que no resultaran en la impiedad deberían ser toleradas, según declaró Erasmo, al igual que las representaciones inapropiadas en las iglesias, los monasterios y las universidades fallidos, y (siempre que no hubiera alternativa) la teología escolástica. ${ }^{77}$ Alguna vez, incluso, Erasmo puso en juego la tolerancia de los judíos y del catolicismo medieval:

\footnotetext{
${ }^{73}$ Contra pseudevangelicos ASD IX-1 304/615-18. Erasmo señala lo mismo contra Martin Bucer, Allen, Ep. 2615: 495-99, y contra el propio Lutero, Hyperaspistes II LB X 1483C-D.

${ }^{74}$ Contra pseudevangelicos ASD IX-1 292/239-40.

${ }^{75}$ Hyperaspistes I LB X 1257F-1258A.

${ }^{76}$ De esu carnium ASD IX-1 38/563-64.

${ }_{77}$ Modus orandi deum ASD V-1 154/135-36 (supersticiones), 163-65 (representaciones); De recta pronuntiatione ASD 1-4 24/344-54 (monasterios, universidades); Allen, Ep. 1127: 14-16 (escolasticismo).
} 
Los apóstoles mostraron tolerancia hacia los judíos, que no podían ser apartados de su arraigado gusto por la Ley; y lo mismo, creo, mostrarían con razón hacia estos hombres que durante tantos siglos han aceptado la autoridad de todos los concilios y papas y distinguidos maestros, y encuentran alguna dificultad para tragar el vino nuevo de esta enseñanza moderna. $^{78}$

Confrontado, entonces, con la idea protestante de que uno puede y debe crear una perfecta sociedad cristiana apartándose de la Iglesia tradicional, Erasmo abandonó su visión de que siempre se debe luchar por la perfección con el fin de hacer al menos algunas mejoras. En lugar de ello, abogó por la tolerancia de la tradición católica, si fuese necesario hasta el final de la historia. Por lo tanto, los ejemplos más convincentes de la tolerancia erasmiana no anuncian modernidad sino que surgen de una preocupación por preservar el catolicismo medieval. En lugar de desarrollar una nueva idea de la tolerancia como un instrumento en contra de las aspiraciones totalitarias de la Iglesia medieval, Erasmo utilizó el concepto existente de tolerancia para oponerse a la no menos totalitaria presunción del protestantismo de que podía realizar, o que incluso representaba, la Ciudad de Dios en la Tierra.

Mi estudio de las actitudes medievales y humanistas hacia la tolerancia me permite sacar algunas conclusiones críticas. Contra las declaraciones de Klaus Schreiner, la pretensión de la Iglesia medieval de representar la verdad absoluta no implica una limitación del significado de la tolerancia. Es en orden a definir su propia actitud hacia quienes no se ajustaron a la verdad absoluta que la Iglesia desarrolló y adoptó la idea de tolerantia. Los herejes (los enemigos desde adentro) fueron perseguidos, pero a los no creyentes, especialmente los judíos (los enemigos de afuera), se les concedió un derecho de existencia, como a la mayoría de los elementos sociales que violaban el código moral que la verdad religiosa absoluta legitimó y santificó. Es también evidente que los estrechos lazos entre la Iglesia y el Estado en la Edad Media no debilitaron el impacto de la tolerancia sino que lo reforzaron. Los autores eclesiásticos mismos aconsejaron a los gobernantes mundanos que adoptaran una actitud tolerante hacia los malhechores, recurriendo al concepto de tolerancia en el derecho canónico y aplicándolo en la esfera secular.

\footnotetext{
${ }^{78}$ CWE, Ep. 1341A: 1172-77, Allen, I, 30: 28-33. Erasmo no habla inequívocamente de "tolerantia" sino de "moderatio". "Enseñanza moderna" refiere al Luteranismo.
} 
La suposición de Schreiner de que la tolerancia implica libertad de religión y pluralidad de verdad me parece fundamentalmente equivocada. En la tradición medieval, la tolerancia es un precepto de no interferencia por parte de aquellos que están en el poder. Una vez que se reconoce la libertad religiosa, la religión se vuelve políticamente neutral y, por lo tanto, ya no ofrece ninguna base para la interferencia o la no interferencia. La libertad religiosa y la tolerantia religiosa son, por lo tanto, lógicamente incompatibles. La pluralidad de la verdad, por otro lado, es compatible con la tolerantia, pero los dos conceptos no se requieren el uno al otro. La tolerancia no se refiere a lo verdadero sino a lo falso. Si la verdad en cuestión es uniforme o plural es irrelevante. La historia en realidad nos enseña que la tolerancia medieval coexistió con una verdad uniforme, mientras que el esfuerzo de pluralizar la verdad religiosa en los tempranos tiempos modernos fue acompañado por una voluntad decreciente de tolerar la desviación social.

Si lo ponemos en términos generales, podríamos decir que la tolerantia medieval define la actitud de la civilización cristiana hacia su propia contraparte. Dentro del rango de la civilización cristiana prevalece un conjunto de reglas absolutas (de ahí la persecución de los herejes); la tolerantia, sin embargo, ofrece la posibilidad de llegar a un acuerdo con el mundo exterior. Es una forma de llevarse bien con las diferencias culturales esenciales entre la sociedad cristiana y los que permanecen ajenos a ella. Las tendencias supuestamente tolerantes en el pensamiento renacentista, por otro lado, definen sólo las relaciones dentro de civilización cristiana. La concordia erasmiana nos invita a considerar la civilización cristiana como compuesta de reglas relativas, pluriformes. No ofrece ninguna posibilidad, sin embargo, de llegar a un acuerdo con el mundo exterior. De hecho, hay poco espacio para tal mundo: se permiten diferencias culturales inocuas entre los miembros de la sociedad cristiana, pero las diferencias culturales esenciales preferiblemente deberían desaparecer. En contraste con la tolerantia, la concordia significa la renuencia a rechazar a otros, pero no a suprimir al otro rechazado. Nos enseña a aceptar alguna variación dentro del rango de lo civilizado; la tolerantia, por otro lado, nos enseña a vivir con diferencias reales.

La confusión moderna entre las nociones de "concordia" y de "tolerancia" podría ser una herencia de la filosofía ilustrada. En el siglo dieciocho la distinción entre tolerare y approbare del derecho canónico ya no se mantenía. ${ }^{79}$ Cuando Voltaire abogó por la "tole-

\footnotetext{
${ }^{79}$ Schreiner, 533.
} 
rancia" en asuntos religiosos, lo que tenía en mente era la coexistencia pacífica de diferentes sistemas de creencias que, para él, de todos modos no tenía ningún significado real. Así, "tolerancia" llegó a significar poco más que "indiferencia". Esta noción bastante débil de "tolerancia" todavía domina en el discurso político moderno. Cuando hoy en día las personas instan a los políticos (o los políticos instan a las personas) a ser tolerantes, lo que realmente tienen en vista es una actitud indiferente. Admitiendo la relatividad de nuestras verdades, deberíamos ser renuentes a condenar los actos o creencias de nuestro prójimo que difieren de los nuestros -ésa es la idea básica de la así llamada tolerancia. Una idea que nos hace moralmente indefensos si aparece el mal incondicional; una idea, además, que debería hacernos orar para nunca volver a encontrar la verdad absoluta, porque eso aparentemente implicaría el final de la tolerancia.

De la tradición medieval de la tolerancia, podríamos aprender que estas últimas impresiones son incorrectas. Los autores medievales nunca dudaron de que poseían la verdad absoluta, pero desarrollaron el concepto de tolerantia como una forma de llevarse bien con lo falso. Los autores medievales nunca fueron moralmente indefensos contra el mal incondicional y lo condenaron donde creyeron encontrarlo, pero aun así abogaban por no interferir con él si esto parecía ser oportuno. Obviamente no tenemos los mismos enemigos que los medievales. Aun así, con respecto a la cuestión de cómo manejar a los enemigos que tenemos sin ir a los extremos de la tiranía y la inercia, la doctrina medieval de la tolerancia contiene también una lección para nuestra época.

Katholieke Universiteit Nijmegen (Universidad Católica de Nimega) 